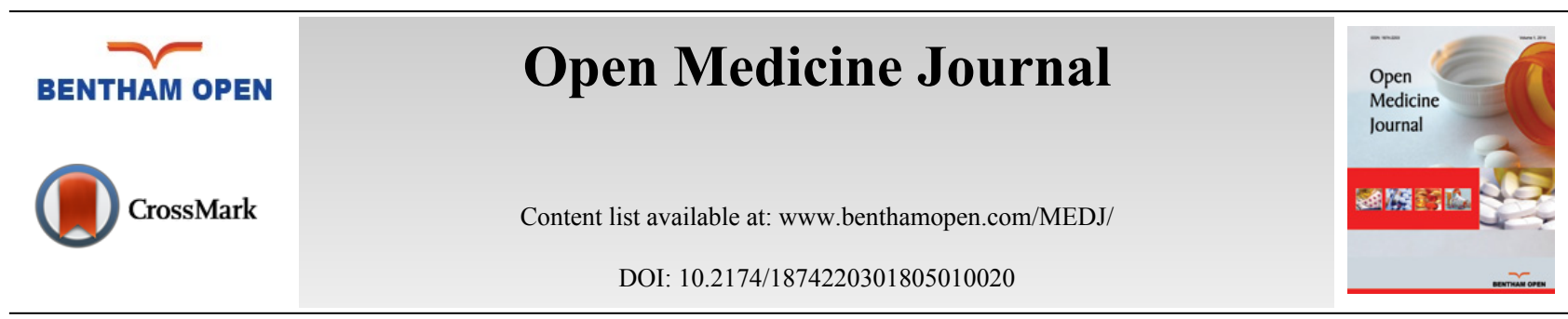

REVIEW ARTICLE

\title{
Adiponectin and Inflammation in Health and Disease: An Update
}

\author{
Alice G. Geagea ${ }^{1}$, Samir Mallat ${ }^{2, *}$, Charbel F. Matar ${ }^{2}$, Raymond Zerbe ${ }^{1}$, Estelle Filfili ${ }^{1}$, Maria \\ Francis $^{1}$, Hanine Haidar $^{1}$ and Abdo Jurjus ${ }^{1, *}$ \\ ${ }^{I}$ Department of Anatomy, Cell Biology and Physiological Sciences, Faculty of Medicine, American University of Beirut \\ (AUB), Beirut, Lebanon \\ ${ }^{2}$ Department of Internal Medicine, American University of Beirut Medical Center (AUBMC), Beirut, Lebanon
}

Received: April 12, 2018

Revised: May 6, 2018

Accepted: May 12, 2018

\begin{abstract}
Adiponectin, a protein secreted by adipocytes, gained a special medical attention in the past two decades mostly due to its relation to obesity, a major health problem worldwide. Moreover, adiponectin has shown to have a preventive effect on insulin resistance, diabetes and cardiovascular diseases. Lately, obesity has been classified as a chronic inflammatory state, whereby dysregulated adipocytes and high infiltration of macrophages shift toward the production of pro-inflammatory cytokines like TNF- $\alpha$ and IL-6 among others. This status contributes to a decrease in adiponectin levels, thus leading to the emergence of obesity related complications. This review will focus on the hormone adiponectin and its mechanisms of action in relation to insulin resistance, diabetes, cardiovascular effect and atherosclerosis. It will also cover the various therapeutic approaches aiming to increase the levels of this important cytokine, and to highlight the promising role of AdipoRon, an adiponectin receptor agonist, and of diet.
\end{abstract}

Keywords: Adiponectin, Obesity, TNF- $\alpha$, IL-6, Cytokine, AdipoRon.

\section{INTRODUCTION}

Adiponectin is a specific protein secreted by adipocytes with presumptive anti-atherogenic and anti-inflammatory characteristics [1]. It is documented that increases in the adipose mass are associated with a rise in the proportion of adipose tissue macrophages, as well as a variety of metabolic and endocrine complications [2]. Actually, multiple molecules released by adipocytes may contribute to the development of insulin resistance, Type2 Diabetes Mellitus (T2DM) and Hypertension (HTN) [3]. Such complications are intensely connected to the levels of pro-inflammatory cytokines (e.g. TNF- $\alpha$, IL-6), among other factors [4]. On the other hand, adiponectin is reduced in obese and diabetic subjects. A study comparing the levels of adiponectin between obese and non-obese individuals has found that it is lower in obese subjects and a strong negative correlation existed between adiponectin levels and Body Mass Index (BMI) [5]. One possible explanation is that TNF- $\alpha$ inhibits adiponectin production by reducing its gene expression through the phosphorylation of Jun-N-Terminal Kinase (JNK), which suppresses PPAR-gamma activity on DNA. This mechanism was confirmed by demonstrating that adiponectin mRNA expression in adipocytes treated with TNF- $\alpha$ was increased following the addition of a JNK inhibitor [6]. Such a low adiponectin state, along with the increase in the synthesis of pro-inflammatory cytokines, promotes the development of insulin resistance. In addition, the dysfunctional adiponectin and insulin signaling pathways predispose to metabolic and vascular complications [7]. This article will shed light on the most recent data concerning the production and the multiple functions of adiponectin as well as the respective mechanisms of action; the co-existence of hypoadiponectinemia with a wide range of diseases linked to insulin resistance such as Coronary Artery Disease (CAD) and Hypertension (HTN) will be also covered.

\footnotetext{
* Address correspondence to this author at the Department of Anatomy, Cell Biology and Physiological Sciences, Faculty of Medicine, American University of Beirut, Beirut, Lebanon, P.O. Box 110236/41 Riad El Solh, Beirut 1107-2020 Beirut, Lebanon; Tel: 00961350000; Ext. 4785, Fax: 009611480687; E-mail: aj00@aub.edu.lb

* Address Co-correspondence to this author at the Department of Internal Medicine, Division Nephrology, American University of Beirut Medical Center (AUBMC), Beirut, Lebanon P.O. Box 110236/41 Riad El Solh, Beirut 1107-2020 Beirut, Lebanon; E-mail: sm104@aub.edu.lb
} 


\section{OBESITY: A WORLDWIDE PROBLEM}

Obesity is now considered as a serious health problem worldwide, creating an economic burden on the health care systems [8] of rich as well as poor countries. Body Mass Index (BMI) is a commonly used method to define obesity, a BMI of $30 \mathrm{~kg} / \mathrm{m} 2$ or more is a cutoff point in the diagnosis of obesity. It is also used to classify obesity; class 1 - mild obesity BMI of 30.0 - $34.9 \mathrm{~kg} / \mathrm{m} 2$, class 2 - moderate obesity BMI of 35.0 to $39.9 \mathrm{~kg} / \mathrm{m} 2$ and, class 3 - extreme obesity BMI of $40.0 \mathrm{~kg} / \mathrm{m} 2$ and above [9]. Data from 2013 showed that the prevalence of obesity among adults was $32,8 \%$ in USA, 21, $1 \%$ in Canada, 28,7\% in Australia, 27.7\% in Lebanon, 35.8\% in Saudi Arabia [10] and from 30\% to $70 \%$ in the Eastern Mediterranean Region (EMR) [11]. In 2016, a double increase in the prevalence of obesity worldwide was reported [12]. In 2014, the number of adults affected by obesity has exceeded 600 million [11].Approximately 300,000 adults in the US die yearly due to a disease related to obesity being also ranked, as one of the primary causes of death [13]. Obesity is common risk factor for Type2 Diabetes (T2DM), Coronary Artery Disease(CAD), Hypertension (HTN) and dyslipidemia, the co-occurrence of these three disease entities is termed as the Metabolic Syndrome [14].As obesity being the most common cause of insulin resistance, obesity epidemic is the leading cause in the rise of T2DM incidence [15]. Data collected from 2011 revealed that T2DM is now affecting around 285 million people worldwide, with a probability that this number will rise to 439 million by the year of 2030 [16] with 25 million in the United States alone. Nowadays, obesity is ranked, as one of the primary causes of death in the US [13]. It is imperative to point that this epidemic is not only affecting adult but also it has become an emerging problem among children and adolescents; 155 million and 30 to 45 million children are overweight and obese, respectively [17]. Moreover, it has been shown that infanthood obesity increased worldwide from 1990 to 2010 , to reach a prevalence of $6.7 \%$ in 2010 . It is also expected that it would extend more by 2020 with a prevalence of $9.1 \%$ [11 - 18].

\section{ADIPOSE TISSUE: AN ENDOCRINE ORGAN}

There are functionally and developmentally two types of adipose tissues in mammals, white and brown adipose tissues. The brown adipose tissue is preponderant among human newborns and hibernating mammals, it generally richer in mitochondria and capillaries than the second type. Its role is basically in heat production. On the other hand, the second type, the white adipose tissue, has a well-established role in energy storage and is responsible of regulating fatty acid homeostasis [8]. It is a type of a soft connective tissue composed of adipocytes encompassed by a complex extracellular matrix including collagen fibers, blood vessels, fibroblasts, mast cells and immune cells among other constituents [19]. When caloric intake exceeds consumption, Free Fatty Acids (FFAs) are esterified to glycerol, stored in the white adipose tissue as triglycerides and then released into the blood in case of low caloric intake. On the long run, an extra storage of fat leads to obesity, with a gender specific distribution, and accumulation of visceral fat [20, 21], which increases the risk of developing insulin resistance, Type 2 Diabetes Mellitus (T2DM), cardiovascular diseases, hypertension, and dyslipidemia [22] among others. In addition to its role in energy storage, many studies have depicted the endocrine role of the adipose tissue after the discovery of the hormone leptin [23, 24], secreting adipocytokines and other biologically active molecules including: adiponectin [25, 26], inflammatory cytokines (TNF- $\alpha$ and IL-6), coagulation and complement factors (plasminogen activator inhibitor-1 and fibrinogen), as well as components of the renin-angiotensin aldosterone system (angiotensinogen and renin) [19]. Such an array of secretory molecules possess a wide range of activities in human multiple organ-systems, in particular, the cardiovascular system [27].

\section{ADIPONECTIN CHEMISTRY AND SECRETION}

Adiponectin is an adipocytokine secreted by the White Adipose Tissue (WAT).It is known with the following names; 30-kDa adipocyte complement-related protein, Acrp30, adipoQ, APM-1, and gelatin-binding protein-28 or GBP28 [28]. This adipocytokine is composed of 244 amino acids, shares structural resemblance with collagen and TNF- $\alpha$ [29], and comprises an N-terminal collagenous domain and a C-terminal globular domain. It has 3 different molecular weights: Low, middle and high molecular weights (trimer, hexamer and 12 to 18 multimer adiponectin respectively) [30]. Studies have shown that adiponectin has insulin-sensitizing actions, mostly exerted by its high molecular weight [31], in addition to anti-inflammatory and anti-atherogenic effects [32, 33]. Adiponectin exerts its effects through interaction with two receptors: AdipoR1 and AdipoR2. Each receptor is composed of an intracellular NH2-terminal domain, an extracellular $\mathrm{COOH}$-terminal domain, and has seven trans-membrane domains that are distinct from the G-protein coupled receptors [7]. AdipoR1 is abundantly expressed throughout the body but mainly in the muscle, while AdipoR2 is highly expressed in the liver [31]. Moreover, it is doubtful whether a surface molecule, T cadherin, is a binding protein or a receptor of adiponectin [34]. Instead, its role in the regulation of cardiac, endothelial and Vascular Smooth Muscle Cells (VSMCs) proliferation, migration and survival is well known [35]. Levels of 
adiponectin differ between genders with higher adiponectin levels among females than males. Studies suggested that sexual hormones, like estrogen and testosterone, have a role in regulating adiponectin plasma levels; however, its mechanism of action needs further studies [36, 37]. These sexual characteristics might probably clarify why men are more prone to insulin resistance and atherosclerosis than women [38, 39].

\section{ADIPONECTIN INSULIN SENSITIZING ACTION}

Adiponectin through its binding to adipoR1 activates and induces the phosphorylation of the AMPK pathway [40], leading to an increase in the utilization of glucose and the oxidation of fatty acids in muscle and liver [41, 42]. In addition, this binding promotes extracellular calcium ion $\left(\mathrm{ca}^{2+}\right)$ entry, leading to activation of $\mathrm{ca}^{2+} / \mathrm{calmodulin}^{2}$ dependent protein kinase kinase-b (CaMKK)b necessary for AMPK activation [43]. On the other hand, Adiponectin can bind and activate AdipoR2, thus enhancing fatty acid oxidation through activating PPARa and the expression of its related genes [40]. Subsequently, PPARg coactivator (PGC)-1a expression is increased along with an increase in mitochondria in myocytes [43]. Adiponectin also decreases glucose production by the liver through the reduction of mRNA expression of phosphoenolpyruvate carboxykinase and glucose-6-phosphatase; two essential enzymes in gluconeogenesis [31]. Furthermore, adiponectin could work on the ceramide signaling pathway. It induces the activation of ceramidase; therefore, lowers the hepatic ceramide levels leading to an improvement in insulin sensitivity. On the contrary, a fall in adiponectin levels can lead to high ceramide in the liver, which could be involved in insulin resistance [43] (Fig. 1).

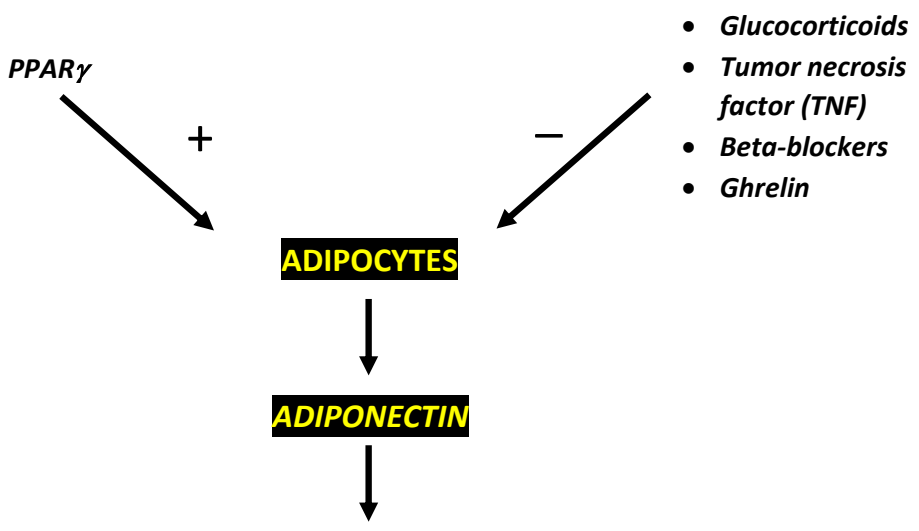

SELF ASSOCIATION TO FORM A CIRCULATING HOMOTRIMER

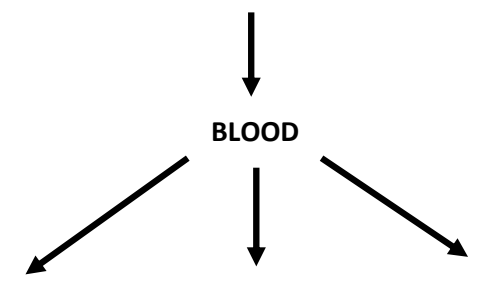

ADIPONECTIN RECEPTORS 1 ADIPONECTIN RECEPTORS 2 T CADHERIN RECEPTORS

ADIPOR1

ADIPOR2

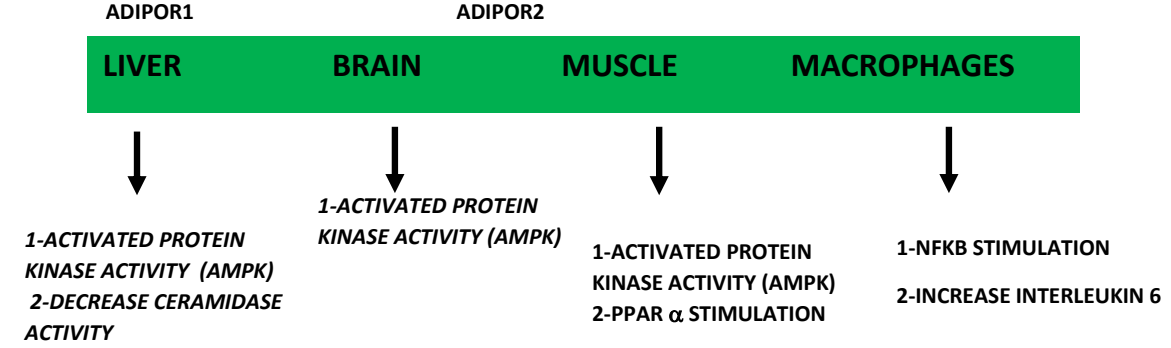

Fig. (1). Adiponectin from secretion to action. 


\section{ADIPONECTIN CARDIOPROTECTIVE EFFECTS}

In vitro studies show that adiponectin decreases macrophages phagocytic activity, inhibits their transformation into foam cells [44, 45], and enhances Nitric Oxide (NO) production by PI3 kinase/Akt-mediated phosphorylation and activation of eNOS [46]. Moreover, adiponectin decreases the production of TNF- $\alpha$ [40], and also reduces its effect on enhancing the expression of Vascular Cell Adhesion Molecule-1 (VCAM-1), Endothelial-leukocyte adhesion molecule-1 (E-selectin) and Intercellular Cell-Adhesion Molecule 1 (ICAM-1), thus, decreasing the adhesion of monocytes to the endothelial cells [44]. Furthermore, when attached to Platelet-Derived Growth Factor-BB (PDGF-BB) and inhibiting the growth-factor stimulated ERK (extracellular-signal-regulated kinase) signaling, adiponectin attenuates the proliferation of Vascular Smooth Muscle Cells (VSMCs) [44]. Moreover, in vivo studies in adiponectin knockout mice show high expression of TNF- $\alpha$ mRNA [47]. Besides, epidemiological studies, conducted in humans, recognize that individuals with low adiponectin levels are more prone to heart diseases, thus identifying it cardiovascular protective effect [48]. However, it is important to note that $\mathrm{T}$ cadherin has a significant role in the expression adiponectin cardioprotective effect [49]. It has been shown that adiponectin induces the expression of mRNA and, therefore, the protein synthesis of tissue inhibitor of metalloproteinase in macrophages by increasing the production of IL-10. It also inhibits the apoptosis of endothelial cells, thus, it protects against plaque rupture through the inhibition of matrix metalloproteinase activity [50].

\section{OBESITY AS A CHRONIC INFLAMMATORY STATE ASSOCIATED WITH LOW ADIPONECTIN LEVELS}

Obesity is a chronic inflammatory state, in which adipocytes, because of high nutritional intake, undergo hypertrophy and hyperplasia, such a situation leads to cellular stress that induces oxidative stress and an inflammatory response in the adipose tissue [8]. The hypertrophied adipocytes along with the resident immune cells of the adipose tissue synthetizes a high amount of pro-inflammatory cytokines including TNF- $\alpha$ [51]. In fact, during obesity, there is a marked accumulation of immune cells in the stromal fraction of adipose tissue. This infiltration of the expanded adipose tissue leads to hypoxia, followed by accumulation of macrophages to participate in the angiogenesis process [40]. However, a difference is noted between the adipose tissue from lean compared to obese individuals. The adipose tissue from lean subjects produces a great proportion of anti-inflammatory cytokines such as adiponectin, Transforming Growth Factor Beta (TGFB), Interleukin (IL)-10, IL-4, IL-13, IL-1 Receptor antagonist (IL-1Ra), and apelin. On the other hand, the adipose tissue from obese subjects produces mostly pro-inflammatory cytokines such as TNF- $\alpha$, IL-6, leptin, visfatin, resistin, angiotensin II, and plasminogen activator inhibitor 1 [51]. Two subtypes of macrophages (M1 and M2) have been described in the adipose tissue of obese people. The M1 subtype secretes pro-inflammatory cytokines such as IL-1b, IL-6, TNF- $\alpha$ [52], iNOS and Reactive Oxygen Species (ROS) [40], which can interfere with insulin signaling and adipogenesis in adipocytes. On the other hand, the M2 subtype produces anti-inflammatory cytokines such as IL-10 [52], IL1 receptor antagonists and arginase-1 [34]. They play a role in tissue remodeling and in the protection against obesity induced insulin resistance [53]. In distinction to mice, the presence of M1 and M2 subsets of macrophages has not been established in human, but rather a mix between M1 and M2 has been observed. In fact, obesity causes a switch from M2 phenotype to M1 phenotype, thus contributing to insulin resistance in mice and human [54]. Interestingly, inducing weight loss by exercise or even by bariatric surgery causes a decrease in the number of adipose tissue macrophages along with a decrease in the pro-inflammatory markers in both the adipose tissue and in the plasma [52]. In addition, it has been shown that the adaptive immune system also plays a role in the obesity associated inflammatory state, whereby the early infiltrating lymphocytes may contribute to inflammation by activating and amplifying the number of adipose tissue macrophages [55]. In an animal model of obesity, a high number of cytotoxic CD8+ cells has been observed to participate in the stimulation and recruitment of adipose tissue macrophages along with the triggering of the pro-inflammatory cascades linked to insulin resistance [56]. Similar to the switch from the anti-inflammatory M2 macrophages to the pro-inflammatory M1 macrophages in obesity, there is a change in the balance between the T helper 1 and $\mathrm{T}$ helper 17 lymphocytes, which are pro-inflammatory CD4+ cells, and the T helper 2 and regulatory $\mathrm{T}$ lymphocytes, which are anti-inflammatory CD4+ cells; causing the release of cytokines from the recently recruited macrophages [52]. Besides, it is important to highlight the fact that the switch from the proinflammatory macrophages M1 to the anti-inflammatory macrophages M2 is achieved through an AMPK dependent mechanism [43, 57]. In addition, it has been shown that obesity does not only reduce adiponectin levels but also it decreases the expression of its receptors AdipoR1/R2. In ob/ob mice, a reduction in adiponectin associated AMPK is observed in the skeletal muscle. This is an indicator that low expression of AdipoR 1 and AdipoR2 in obesity is connected with insulin resistance [43]. The increased levels of TNF- $\alpha$ from the dysfunctional adipose tissue in obesity 
might explain the negative association between visceral adiposity and adiponectin levels [50]. The oxidative stress, the chronic inflammatory state and its pro-inflammatory cytokines, along with the infiltration of macrophages and the release of ROS in adipose tissue of obese individuals, can cause the inhibition of adiponectin gene expression and thus could be a reason behind the low adiponectin level in obesity [58]. Interestingly, based on the fact that adiponectin has an anti-inflammatory role on endothelial cells and macrophages, therefore, the hypoadiponectinemia in obesity makes the pro-inflammatory status worse, forming a vicious circle that lowers more the adiponectin [59].

\section{INSULIN SIGNALING PATHWAY AND THE MECHANISM OF INSULIN RESISTANCE}

The pancreas contains endocrine cells located in the Islets of Langerhans. They produce several hormones including insulin, glucagon and somatostatin, which are important for the maintenance of euglycemia. Insulin is released from the pancreas in response to the circulating increased glucose [60]. This hormone enhances the uptake of glucose in the skeletal muscles and adipose tissue, promotes glycogen storage in the skeletal muscle and liver, inhibits gluconeogenesis and glycogenolysis in the liver, and also boosts lipogenesis inside the hepatic and adipose cells, along with the inhibition of lipolysis, therefore, preventing the release FFA's from triacylglycerols [8]. At the molecular level, when Insulin binds to its receptor, its tyrosine kinase is activated leading to the phosphorylation of its tyrosine residues. This step is followed by the phosphorylation of tyrosine residues of the Insulin Receptor Substrates (IRSs) [61]. Phosphorylated IRS1/2 cause an activation of two signaling pathways; the phosphatidylinositol 3-kinase (PI3K)AKT/protein kinase, and the Ras-Mitogen-Activated Protein Kinase (MAPK) pathway [8]. Akt activation plays a central part in promoting the translocation of Glut4 and the synthesis of glycogen [61]. On the other hand, the mechanism of insulin resistance is characterized by an impairment in the insulin signaling pathway in the cells that are responsive to insulin like the adipocytes, myocytes, hepatocytes and the -cells. After the establishment of the insulin resistant state, many patients develop Beta cell failure, triggering the onset of Type 2 Diabetes Mellitus (T2DM) [15]. Many clues now suggest that obesity associated inflammation plays a key role in insulin resistance. TNF- $\alpha$ was the first pro-inflammatory cytokine reported to be involved in the initiation and evolution of insulin resistance [51]. Studies on TNF- $\alpha$ in the 1990's demonstrated that when treating adipocytes with TNF- $\alpha$, the insulin signaling is disrupted, specifically due to changes in the transcription of insulin receptor, IRS-1 and Glut4 [62]. TNF- $\alpha$ activates intracellular kinases c-Jun N-Terminal Kinase (JNK) and IkB Kinase (IKK), leading to the phosphorylation of IRS on its ser-307 residues, to the suppression of insulin mediated phosphorylation of IRS-1 tyrosine residues, and the activation of its downstream molecules [15]. In addition, TNF- $\alpha$ increases the expression of cytokine signaling 3 (SOCS3) suppressor that mediates the ubiquitination of IRS1 and IRS2, therefore, interfering with insulin signaling [40]. Moreover, studies using animal models demonstrated that increasing the TNF- $\alpha$ levels cause insulin resistance, and blocking the effects of TNF- $\alpha$ using genetic or pharmacological methods improve the obesity associated insulin resistance [63]. These studies clearly indicate that an inflammatory immune pathway may lead to the development of insulin resistance in obesity.

\section{HYPOADIPONECTINEMIA RELATIONSHIP TO INSULIN RESISTANCE AND TYPE 2 DIABETES}

Recent research revealed that adiponectin levels are associated with the presence of diabetes [64 - 69]. In fact, a study in the Japanese population has shown that total and High Molecular Weight (HMW) adiponectin are negatively correlated with the risk of type 2 diabetes, taking into consideration other confounding variables [64]. Moreover, other studies supported the fact that diabetes risk is lower when adiponectin levels are higher [65], and adiponectin levels are in an inverse relationship with the degree of adiposity, fasting plasma glucose and insulin levels [66]. Furthermore, a nested case-control study showed that adiponectin levels were lower in newly diagnosed diabetics compared to controls. Such findings indicate that adiponectin has an important role in the etiology of T2DM [32]. Furthermore, combined studies do support the theory that adiponectin has an essential role in the development of T2DM. Lately, a few genes linked to adiponectin levels have been recognized. Actually, a cohort study on three different ethnicities indicated that multiple genetic loci related to adiponectin levels have an impact on the risk of insulin resistance and T2DM [67]. Additionally, a diabetes locus has been identified on the chromosome $3 \mathrm{q} 27$, the chromosome where adiponectin gene is present [68]. Another study on Japanese patients with T2DM and non-diabetic matched controls recognized four missense mutations in adiponectin globular domain gene. The I164T mutation was seen in higher frequency in diabetic cases compared to control subjects. Subjects carrying this mutation exhibited some features of the metabolic syndrome and their plasma adiponectin levels were lower than subjects free of this mutation [69]. Combining these findings, one could postulate that alterations in the adiponectin gene that result in less secretion of adiponectin may constitute a cause of the pathophysiology of T2DM. 


\section{HYPOADIPONECTINEMIA LINKED TO CARDIOVASCULAR DISEASES}

The dysfunctional adipose tissue in obesity causes an activation of the renin angiotensin aldosterone system, which is an important player in modulating blood pressure in obesity [70]. It has been demonstrated that in obesity, there is a prominent angiotensin II (AngII) release from the abdominal subcutaneous adipose tissue. Angiotensinogen (AGT), renin, and Angiotensin Converting Enzyme (ACE) were demonstrated in the components of adipose tissue in both animals and humans [71]. Comparing obese with lean individuals, the levels of renin, AGT, and ACE activities were higher in the obese and decreased after weight loss. Such changes correlated with changes in systolic blood pressure and incidence of hypertension [72]. Another explanation of the increased blood pressure in obesity is that excess weight gain can be accompanied with sodium retention and an increase in the volume of extracellular fluid. Such changes can activate the sympathetic nervous system, along with insufficient suppression of the renin-angiotensin-system [73]. On the other hand, some studies have shown that patients with high blood pressure have lower levels of adiponectin than normotensive individuals, and adiponectin levels were negatively correlated with blood pressure [74]. Other studies, focusing on the relationship between low adiponectin levels and body mass index in the development of hypertension, demonstrated that low adiponectin is an independent risk factor for developing hypertension [75]. It has also been shown that obese men with low adiponectin levels had a higher risk of developing hypertension when compared to other obese men with high adiponectin levels. However, the etiology of how low adiponectin could induce hypertension is unclear. As adiponectin induces fatty acid oxidation, the high levels of FFA's in obesity could play a role through the activation of the sympathetic nervous system. Moreover, because adiponectin has anti-oxidative and anti-inflammatory roles, a low adiponectin may increase the risk of developing hypertension by inducing oxidative and inflammatory injuries to the vessels [73]; by inflicting a dysfunctional endothelium mediated vasoreactivity [50]. Furthermore, it is well established that endothelial cell dysfunction is an important event in the pathophysiology of atherosclerosis, plaque disruption and thrombosis. Endothelial cell dysfunction can be initiated by high glucose, angiotensin II and oxidized low-density lipoprotein, also by impaired activity of Nitric Oxide Synthase (eNOS). It is documented that adiponectin counters the effect of angiotensin II on the endothelial cells and prevents their apoptosis by increasing the association between eNOS and heat shock protein 90 (HSP90) [76]. Besides, it is pertinent to know that AngII has an important role in the pathogenesis of hypertension and atherosclerosis. Several studies suggested that AngII can cause insulin resistance. In fact, hypertensive subjects and animal models treated with angiotensin I converting enzyme inhibitors showed an improvement in insulin resistance [77]. Similar results were obtained using AII type 1 receptor (AT1R) blocker [78]. It has been demonstrated that insulin mediated glucose uptake was disrupted in normal rats after 14 days of administering a specific dosage of AngII, probably leading the authors to hypothesize that AngII causes insulin resistance at the intra cellular level, in line a direct decrease in adiponectin levels was observed [79]. Further studies conducted by Furuhashi et al. showed that adiponectin concentrations increased along with improvement in insulin resistance after treatment with AT1R blocker, an angiotensin I converting enzyme inhibitor in patients with essential hypertension [80]. Another study by Kumada et al. has shown that hypoadiponectinemia is an independent risk factor for Coronary Artery Disease (CAD) in men after adjusting for CAD risk factors [48]. Taken all together, one can conclude that AngII in obesity can reduce adiponectin levels, raise blood pressure, and increase the risk of atherosclerosis. The subsequent hypoadiponectinemia causes insulin resistance and can also contribute to the development of hypertension and atherosclerosis.

\section{ADIPONECTIN AND CHRONIC KIDNEY DISEASE}

As illustrated in this text, adiponectin plays a significant role in reducing cardiovascular risk, decreasing insulin resistance, enhancing skeletal muscle glucose uptake and suppressing hepatic glucose production. It has, as well, an anti-inflammatory effect and may play a role in decreasing apoptosis and proliferation in cancer cells [81]. Furthermore, high adiponectin levels have been shown to be inversely related to obesity and associated with reduced cardiovascular risk. Yet, a unique situation prevails in Chronic Kidney Disease (CKD) whereby a high cardiovascular risk persists despite an elevated adiponectin level [82]. Although felt to be elevated because of a low renal clearance, the level of adiponectin in CKD is more complex, thus involving a decrease of fat mass in CKD and an increase of reactive oxidative species (due to inflammation) with consequent down regulation of gene expression [83].In addition, adiponectin has been studied in relation to microalbuminuria in non-diabetic hypertensive patients and in diabetes type 2. It was found that adiponectin is inversely related to the rate of excretion of microalbuminuria without prediction on the decrease in Glomerular Filtration Rate (GFR) [84, 85]. Indeed, detailed experimental studies in mice have shown that Knockout mice for adiponectin showed podocytes effacement and microalbuminuria that resolved easily after adiponectin replacement [86]. Tsigalou et al. have shown that obesity or malnutrition is the driving force for 
hyperadiponectinemia in hemodialysis patients and is linked to increased mortality [87]. Furthermore, the high level in hemodialysis patients has been correlated with a decrease of low mineral density, concluding that adiponectin may play a role in low bone resorption in End Stage Renal Disease patients [88].Paradoxically there was an increase in adiponectin level with severity of disease and progression of T1DM, postulated to be due to an increase in oxidative stress. A feedback due to an elevated adiponectin may be needed to decrease the reactive oxidative stress and NADPH oxidase activity [89].

\section{THERAPEUTIC CONSIDERATIONS}

As adiponectin is an important player in metabolic and cardiovascular balance, it is believed that it can be used in the management of diabetes, metabolic syndrome and cardio-vascular diseases. However, it is important to know that adiponectin itself cannot be used orally because it is mainly a protein which can be degraded by the digestive enzymes, therefore, it will not be able to reach the blood stream [29]. It is believed that there are means to increase the levels of adiponectin, either by increasing its gene expression or by using a mimicker protein [90]. Thiazolidinediones (TZDs) are common insulin sensitizing drugs used in the management of type 2 diabetes. They are ligands of a nuclear receptor found mainly in adipose tissue and called Peroxisome Proliferator Activated Receptor (PPAR)-gamma. PPAR-gamma controls the expression of genes involved in adipocyte differentiation resulting in smaller adipocytes that are more sensitive to insulin, in addition to other genes that mediate the normal balance of glucose and lipids; thus, decreasing the levels of free fatty acids [91, 92]. Clinical trials studied the effects of TZDs treatment. They showed that in fasting plasma glucose, insulin levels became lower after the administration of TZDs along with an improvement in insulin sensitivity in diabetics and an increased in adiponectin plasma levels and its mRNA expression by activating the promotor of adiponectin gene. TZDs also interfered with TNF- suppressive effect on adiponectin production; thus, TZDs by increasing adiponectin levels might have a preventive role against atherosclerosis [93, 94]. Another way to modulate adiponectin actions is by the production of an agonist acting on its receptors. A study that investigated the presence of small molecules that can act on adiponectin receptor has revealed a small molecule named AdipoRon. The administration of this agent resulted in enhanced phosphorylation of AMPK in muscle and liver, decreased fasting plasma glucose and plasma insulin levels along with an increased rate of fatty acid oxidation leading to decreased levels of plasma FFA's and triglycerides [94]. These findings strongly indicate an improvement in insulin sensitivity. Furthermore, AdipoRon significantly attenuated oxidative stress markers and reduced the degree of inflammation in the White Adipose Tissue (WAT). These effects were not observed in adiponectin receptors knockout mice, a finding strongly indicates that AdipoRon acts on AdipoRs. Therefore, adiponectin agonists like AdipoRon could be a possible therapeutic agent in the management of T2DM [95]. The structural composition of AdipoR1 and AdipoR2 should be profoundly investigated in order to optimize AdipoR agonists. Recently, anti-AdipoR antibodies were produced and were able to identify the composition of AdipoRs, and the subsequent crystals obtained from this binding. They also helped in the identification of the crystal structures of AdipoR1 and AdipoR2 [96]. Gaining more insight about their structure gives us a major opportunity to optimize the AdipoR agonist "AdipoRon" and shifts its use as an important class of medication in the management of diabetes [97]. Thus, the adiponectin and its receptors are important targets in the management of obesity linked insulin resistance [98]. Lately, the role of Lactobacillus rhamnosus GG (LGG), a probiotic, in modulating adiponectin levels was elicited; thus indicating the possible role of using the gut microbiota as a target in the treatment of obesity related disorders. A study using animal models showed that oral administration of LGG into mice fed with a specific high fat diet led to an improvement in insulin sensitivity and a decrease in body weight compared to mice fed with a normal diet [99]. A decrease in gluconeogenesis was observed as a result of a suppression of G6Pase and PEPCK expression along with an upregulation of PPAR-a, therefore, glucose and lipid metabolism were improved. An activation of AMPK in skeletal muscle and in the adipose tissues was observed. Furthermore, higher expression of GLUT4 mRNA in skeletal muscle and adiponectin release from the adipose tissue were detected [100].

\section{CONCLUSION}

In summary, low adiponectin levels are linked to many metabolic and cardiovascular complications. As obesity is the most common leading cause of insulin resistance, it is a link to many disease entities like T2DM, dyslipidemia, hypertension and atherosclerosis. Although it is confirmed that adiponectin is lower in obese subjects, this might be a clue to the development of obesity-a worldwide health epidemic- related problems. It is also observed that adiponectin can be low in these diseases, when taken solely, regardless of the presence of obesity. By observing the important role of this cytokine and understanding its normal function, it is imperative to target its levels with a specific therapeutic 
approach and be able to raise its concentrations, which might play role in the management and the prevention of these devastating diseases.

\section{CONSENT FOR PUBLICATION}

Not applicable.

\section{CONFLICT OF INTEREST}

The authors declare no conflict of interest, financial or otherwise.

\section{ACKNOWLEDGEMENTS}

Declared none.

\section{REFERENCES}

[1] Hotta K, Funahashi T, Bodkin NL, et al. Circulating concentrations of the adipocyte protein adiponectin are decreased in parallel with reduced insulin sensitivity during the progression to type 2 diabetes in rhesus monkeys. Diabetes 2001; 50(5): 1126-33.

[http://dx.doi.org/10.2337/diabetes.50.5.1126] [PMID: 11334417]

[2] Weisberg SP, McCann D, Desai M, Rosenbaum M, Leibel RL, Ferrante AW Jr. Obesity is associated with macrophage accumulation in adipose tissue. J Clin Invest 2003; 112(12): 1796-808. [http://dx.doi.org/10.1172/JCI200319246] [PMID: 14679176]

[3] Ghoshal K, Bhattacharyya M. Adiponectin: Probe of the molecular paradigm associating diabetes and obesity. World J Diabetes 2015; 6(1): 151-66. [http://dx.doi.org/10.4239/wjd.v6.i1.151] [PMID: 25685286]

[4] Popko K, Gorska E, Stelmaszczyk-Emmel A, et al. Proinflammatory cytokines Il-6 and TNF- $\alpha$ and the development of inflammation in obese subjects. Eur J Med Res 2010; 15(2)(Suppl. 2): 120-2. [PMID: 21147638]

[5] Maeda K, Okubo K, Shimomura I, Funahashi T, Matsuzawa Y, Matsubara K. Paradoxical decrease of an adipose-specific protein, adiponectin, in obesity. Biochem Biophys Res Commun 1996; 221: 286-9. [http://dx.doi.org/10.1006/bbrc.1996.0587] [PMID: 8619847]

[6] Kim KY, Kim JK, Jeon JH, Yoon SR, Choi I, Yang Y. c-Jun N-terminal kinase is involved in the suppression of adiponectin expression by TNF- $\alpha$ in 3T3-L1 adipocytes. Biochem Biophys Res Commun 2005; 327(2): 460-7. [http://dx.doi.org/10.1016/j.bbrc.2004.12.026] [PMID: 15629137]

[7] Cheng KK, Lam KS, Wang B, Xu A. Signaling mechanisms underlying the insulin-sensitizing effects of adiponectin. Best Pract Res Clin Endocrinol Metab 2014; 28(1): 3-13.

[http://dx.doi.org/10.1016/j.beem.2013.06.006] [PMID: 24417941]

[8] Kwon H, Pessin JE. Adipokines mediate inflammation and insulin resistance. Front Endocrinol (Lausanne) $2013 ; 4: 71$. [http://dx.doi.org/10.3389/fendo.2013.00071] [PMID: 23781214]

[9] Uzogara SG. Obesity epidemic, medical and quality of life consequences: A review. Int J Public Health Res $2017 ; 5(1)$ : 1.

[10] Martinez R. Prevalence of Overweight and Obesity visualization 2015. Available from: http://publichealthintelligence.org/content/prevalence -overweight-and-obesity-worldwide

[11] Mallat S, Geagea AG, Jurjus R, et al. Obesity in lebanon: A national problem. World J Cardiovasc Dis 2016; 6(6): 166. [http://dx.doi.org/10.4236/wjcd.2016.66017]

[12] Arroyo-Johnson C, Mincey KD. Obesity epidemiology worldwide. Gastroenterol Clin North Am 2016; 45(4): 571-9. [http://dx.doi.org/10.1016/j.gtc.2016.07.012] [PMID: 27837773]

[13] Mokdad AH, Ford ES, Bowman BA, et al. Prevalence of obesity, diabetes, and obesity-related health risk factors, 2001. JAMA 2003; 289(1): 76-9.

[http://dx.doi.org/10.1001/jama.289.1.76] [PMID: 12503980]

[14] Kadowaki T, Yamauchi T, Kubota N, Hara K, Ueki K, Tobe K. Adiponectin and adiponectin receptors in insulin resistance, diabetes, and the metabolic syndrome. J Clin Invest 2006; 116(7): 1784-92. [http://dx.doi.org/10.1172/JCI29126] [PMID: 16823476]

[15] Johnson AM, Olefsky JM. The origins and drivers of insulin resistance. Cell 2013; 152(4): 673-84. [http://dx.doi.org/10.1016/j.cell.2013.01.041] [PMID: 23415219]

[16] Chen L, Magliano DJ, Zimmet PZ. The worldwide epidemiology of type 2 diabetes mellitus--present and future perspectives. Nat Rev Endocrinol 2011; 8(4): 228-36. [http://dx.doi.org/10.1038/nrendo.2011.183] [PMID: 22064493]

[17] Mirmiran P, Sherafat-Kazemzadeh R, Jalali-Farahani S, Azizi F. Childhood obesity in the Middle East: A review. East Mediterr Health J 
2010; 16(9): 1009-17.

[http://dx.doi.org/10.26719/2010.16.9.1009] [PMID: 21218730]

[18] Mazarello Paes V, Ong KK, Lakshman R. Factors influencing obesogenic dietary intake in young children (0-6 years): systematic review of qualitative evidence. BMJ Open 2015; 5(9): e007396. [http://dx.doi.org/10.1136/bmjopen-2014-007396] [PMID: 26377503]

[19] Ahima RS, Flier JS. Adipose tissue as an endocrine organ. Trends Endocrinol Metab 2000; 11(8): $327-32$. [http://dx.doi.org/10.1016/S1043-2760(00)00301-5] [PMID: 10996528]

[20] Galic S, Oakhill JS, Steinberg GR. Adipose tissue as an endocrine organ. Mol Cell Endocrinol 2010; 316(2): 129-39. [http://dx.doi.org/10.1016/j.mce.2009.08.018] [PMID: 19723556]

[21] Reaven GM. Banting lecture 1988. Role of insulin resistance in human disease. Diabetes 1988; 37(12): $1595-607$. [http://dx.doi.org/10.2337/diab.37.12.1595] [PMID: 3056758]

[22] Kissebah AH, Krakower GR. Regional adiposity and morbidity, physiological reviews 1994.

[23] Trayhurn P, Beattie JH. Physiological role of adipose tissue: White adipose tissue as an endocrine and secretory organ. Proc Nutr Soc 2001; 60(3): 329-39. [http://dx.doi.org/10.1079/PNS200194] [PMID: 11681807]

[24] Zhang Y, Proenca R, Maffei M, Barone M, Leopold L, Friedman JM. Positional cloning of the mouse obese gene and its human homologue. Nature 1994; 372(6505): 425-32. [http://dx.doi.org/10.1038/372425a0] [PMID: 7984236]

[25] Díez JJ, Iglesias P. The role of the novel adipocyte-derived hormone adiponectin in human disease. Eur J Endocrinol 2003; 148(3): 293-300. [http://dx.doi.org/10.1530/eje.0.1480293] [PMID: 12611609]

[26] Prins JB. Adipose tissue as an endocrine organ. Best Pract Res Clin Endocrinol Metab 2002; 16(4): 639-51. [http://dx.doi.org/10.1053/beem.2002.0222] [PMID: 12468412]

[27] Jurjus A, Eid A, Al Kattar S, et al. Inflammatory bowel disease, colorectal cancer and type 2 diabetes mellitus: The links. BBA Clin 2015; 5: 16-24.

[http://dx.doi.org/10.1016/j.bbacli.2015.11.002] [PMID: 27051585]

[28] Scherer PE, Williams S, Fogliano M, Baldini G, Lodish HF. A novel serum protein similar to C1q, produced exclusively in adipocytes. J Biol Chem 1995; 270(45): 26746-9. [http://dx.doi.org/10.1074/jbc.270.45.26746] [PMID: 7592907]

[29] Fisman EZ, Tenenbaum A. Adiponectin: A manifold therapeutic target for metabolic syndrome, diabetes, and coronary disease? Cardiovasc Diabetol 2014; 13(1): 103 . [http://dx.doi.org/10.1186/1475-2840-13-103] [PMID: 24957699]

[30] Pajvani UB, Du X, Combs TP, et al. Structure-function studies of the adipocyte-secreted hormone Acrp30/adiponectin. Implications fpr metabolic regulation and bioactivity. J Biol Chem 2003; 278(11): 9073-85. [http://dx.doi.org/10.1074/jbc.M207198200] [PMID: 12496257]

[31] Antuna-Puente B, Feve B, Fellahi S, Bastard JP. Adipokines: The missing link between insulin resistance and obesity. Diabetes Metab 2008; 34(1): 2-11. [http://dx.doi.org/10.1016/j.diabet.2007.09.004] [PMID: 18093861]

[32] Spranger J, Kroke A, Möhlig M, et al. Adiponectin and protection against type 2 diabetes mellitus. Lancet 2003; 361(9353): 226-8. [http://dx.doi.org/10.1016/S0140-6736(03)12255-6] [PMID: 12547549]

[33] Kubota N, Terauchi Y, Yamauchi T, et al. Disruption of adiponectin causes insulin resistance and neointimal formation. J Biol Chem 2002; 277(29): 25863-6 [http://dx.doi.org/10.1074/jbc.C200251200] [PMID: 12032136]

[34] Hug C, Wang J, Ahmad NS, Bogan JS, Tsao TS, Lodish HF. T-cadherin is a receptor for hexameric and high-molecular-weight forms of Acrp30/adiponectin. Proc Natl Acad Sci USA 2004; 101(28): 10308-13. [http://dx.doi.org/10.1073/pnas.0403382101] [PMID: 15210937]

[35] Matsuda M, Shimomura I, Sata M, et al. Role of adiponectin in preventing vascular stenosis. The missing link of adipo-vascular axis. J Biol Chem 2002; 277(40): 37487-91. [http://dx.doi.org/10.1074/jbc.M206083200] [PMID: 12138120]

[36] Combs TP, Berg AH, Rajala MW, et al. Sexual differentiation, pregnancy, calorie restriction, and aging affect the adipocyte-specific secretory protein adiponectin. Diabetes 2003; 52(2): 268-76. [http://dx.doi.org/10.2337/diabetes.52.2.268] [PMID: 12540596]

[37] Xu A, Chan KW, Hoo RL, et al. Testosterone selectively reduces the high molecular weight form of adiponectin by inhibiting its secretion from adipocytes. J Biol Chem 2005; 280(18): 18073-80. [http://dx.doi.org/10.1074/jbc.M414231200] [PMID: 15760892]

[38] Frias JP, Macaraeg GB, Ofrecio J, Yu JG, Olefsky JM, Kruszynska YT. Decreased susceptibility to fatty acid-induced peripheral tissue insulin resistance in women. Diabetes 2001; 50(6): 1344-50. [http://dx.doi.org/10.2337/diabetes.50.6.1344] [PMID: 11375335] 
[39] Kalin MF, Zumoff B. Sex hormones and coronary disease: A review of the clinical studies. Steroids 1990; 55(8): 330-52. [http://dx.doi.org/10.1016/0039-128X(90)90058-J] [PMID: 2237942]

[40] Cao H. Adipocytokines in obesity and metabolic disease. J Endocrinol 2014; 220(2): T47-59. [http://dx.doi.org/10.1530/JOE-13-0339] [PMID: 24403378]

[41] Yamauchi T, Kamon J, Minokoshi Y, et al. Adiponectin stimulates glucose utilization and fatty-acid oxidation by activating AMP-activated protein kinase. Nat Med 2002; 8(11): 1288-95. [http://dx.doi.org/10.1038/nm788] [PMID: 12368907]

[42] Tomas E, Tsao TS, Saha AK, et al. Enhanced muscle fat oxidation and glucose transport by ACRP30 globular domain: acetyl-CoA carboxylase inhibition and AMP-activated protein kinase activation. Proc Natl Acad Sci USA 2002; 99(25): 16309-13. [http://dx.doi.org/10.1073/pnas.222657499] [PMID: 12456889]

[43] Yamauchi T, Iwabu M, Okada-Iwabu M, Kadowaki T. Adiponectin receptors: A review of their structure, function and how they work. Best Pract Res Clin Endocrinol Metab 2014; 28(1): 15-23. [http://dx.doi.org/10.1016/j.beem.2013.09.003] [PMID: 24417942]

[44] Okamoto Y, Kihara S, Funahashi T, Matsuzawa Y, Libby P. Adiponectin: A key adipocytokine in metabolic syndrome. Clin Sci (Lond) 2006; 110(3): 267-78.

[http://dx.doi.org/10.1042/CS20050182] [PMID: 16464169]

[45] Ouchi N, Kihara S, Arita Y, et al. Adipocyte-derived plasma protein, adiponectin, suppresses lipid accumulation and class A scavenger receptor expression in human monocyte-derived macrophages. Circulation 2001; 103(8): 1057-63. [http://dx.doi.org/10.1161/01.CIR.103.8.1057] [PMID: 11222466]

[46] Margaritis M, Antonopoulos AS, Digby J, et al. Interactions between vascular wall and perivascular adipose tissue reveal novel roles for adiponectin in the regulation of enos function in human vessels. Circulation 2013; 127: 2209-21. [http://dx.doi.org/10.1161/CIRCULATIONAHA.112.001133] [PMID: 23625959]

[47] Maeda N, Shimomura I, Kishida K, et al. Diet-induced insulin resistance in mice lacking adiponectin/ACRP30. Nat Med 2002; 8(7): 731-7. [http://dx.doi.org/10.1038/nm724] [PMID: 12068289]

[48] Kumada M, Kihara S, Sumitsuji S, et al. Association of hypoadiponectinemia with coronary artery disease in men. Arterioscler Thromb Vasc Biol 2003; 23(1): 85-9.

[http://dx.doi.org/10.1161/01.ATV.0000048856.22331.50] [PMID: 12524229]

[49] Denzel MS, Scimia MC, Zumstein PM, Walsh K, Ruiz-Lozano P, Ranscht B. T-cadherin is critical for adiponectin-mediated cardioprotection in mice. J Clin Invest 2010; 120(12): 4342-52. [http://dx.doi.org/10.1172/JCI43464] [PMID: 21041950]

[50] Van Gaal LF, Mertens IL, De Block CE. Mechanisms linking obesity with cardiovascular disease. Nature 2006; 444(7121): 875-80. [http://dx.doi.org/10.1038/nature05487] [PMID: 17167476]

[51] Makki K, Froguel P, Wolowczuk I. Adipose tissue in obesity-related inflammation and insulin resistance: cells, cytokines, and chemokines. ISRN Inflamm 2013; 2013: 139239. [http://dx.doi.org/10.1155/2013/139239] [PMID: 24455420]

[52] Esser N, Legrand-Poels S, Piette J, Scheen AJ, Paquot N. Inflammation as a link between obesity, metabolic syndrome and type 2 diabetes. Diabetes Res Clin Pract 2014; 105(2): 141-50. [http://dx.doi.org/10.1016/j.diabres.2014.04.006] [PMID: 24798950]

[53] Tilg H, Moschen AR. Inflammatory mechanisms in the regulation of insulin resistance development. 2008.

[54] Lumeng CN, Bodzin JL, Saltiel AR. Obesity induces a phenotypic switch in adipose tissue macrophage polarization. J Clin Invest 2007; 117(1): 175-84. [http://dx.doi.org/10.1172/JCI29881] [PMID: 17200717]

[55] Tilg H, Moschen AR. Adipocytokines: mediators linking adipose tissue, inflammation and immunity. Nat Rev Immunol 2006; 6(10): 772-83. [http://dx.doi.org/10.1038/nri1937] [PMID: 16998510]

[56] Lee BC, Lee J. Cellular and molecular players in adipose tissue inflammation in the development of obesity-induced insulin resistance. Biochim Biophys Acta 2014; 1842(3): 446-62. [http://dx.doi.org/10.1016/j.bbadis.2013.05.017] [PMID: 23707515]

[57] Ohashi K, Parker JL, Ouchi N, et al. Adiponectin promotes macrophage polarization toward an anti-inflammatory phenotype. J Biol Chem 2010; 285(9): 6153-60. [http://dx.doi.org/10.1074/jbc.M109.088708] [PMID: 20028977]

[58] Engeli S, Feldpausch M, Gorzelniak K, et al. Association between adiponectin and mediators of inflammation in obese women. Diabetes 2003; 52(4): 942-7. [http://dx.doi.org/10.2337/diabetes.52.4.942] [PMID: 12663465]

[59] Guerre-Millo M. Adiponectin: an update. Diabetes Metab 2008; 34(1): 12-8. [http://dx.doi.org/10.1016/j.diabet.2007.08.002] [PMID: 18069030]

[60] Stagner JI, Samols E, Weir GC. Sustained oscillations of insulin, glucagon, and somatostatin from the isolated canine pancreas during 
exposure to a constant glucose concentration. J Clin Invest 1980; 65(4): 939-42. [http://dx.doi.org/10.1172/JCI109750] [PMID: 6987271]

[61] Lee BC, Lee J. Cellular and molecular players in adipose tissue inflammation in the development of obesity-induced insulin resistance. Biochim Biophys Acta 2014; 1842(3): 446-62. [http://dx.doi.org/10.1016/j.bbadis.2013.05.017] [PMID: 23707515]

[62] Stephens JM, Pekala PH. Transcriptional repression of the C/EBP-alpha and GLUT4 genes in 3T3-L1 adipocytes by tumor necrosis factoralpha. Regulations is coordinate and independent of protein synthesis. J Biol Chem 1992; 267(19): 13580-4. [PMID: 1618860]

[63] Cheung AT, Ree D, Kolls JK, Fuselier J, Coy DH, Bryer-Ash M. An in vivo model for elucidation of the mechanism of tumor necrosis factor$\alpha$ (TNF- $\alpha$ )-induced insulin resistance: evidence for differential regulation of insulin signaling by TNF- $\alpha$. Endocrinology 1998 ; $139(12)$ : 4928-35. [http://dx.doi.org/10.1210/endo.139.12.6336] [PMID: 9832430]

[64] Goto A, Noda M, Goto M, et al. Plasma adiponectin levels, ADIPOQ variants, and incidence of type 2 diabetes: A nested case-control study. Diabetes Res Clin Pract 2017; 127: 254-64. [http://dx.doi.org/10.1016/j.diabres.2017.03.020] [PMID: 28407551]

[65] Li S, Shin HJ, Ding EL, van Dam RM. Adiponectin levels and risk of type 2 diabetes: a systematic review and meta-analysis. JAMA 2009; 302(2): 179-88. [http://dx.doi.org/10.1001/jama.2009.976] [PMID: 19584347]

[66] Ryo M, Nakamura T, Kihara S, et al. Adiponectin as a biomarker of the metabolic syndrome. Circ J 2004; 68(11): 975-81. [http://dx.doi.org/10.1253/circj.68.975] [PMID: 15502375]

[67] Dastani Z, Hivert MF, Timpson N, et al. Novel loci for adiponectin levels and their influence on type 2 diabetes and metabolic traits: a multiethnic meta-analysis of 45,891 individuals. PLoS Genet 2012; 8(3): e1002607. [http://dx.doi.org/10.1371/journal.pgen.1002607] [PMID: 22479202]

[68] Vionnet N, Hani EH, Dupont S, et al. Genomewide search for type 2 diabetes-susceptibility genes in French whites: evidence for a novel susceptibility locus for early-onset diabetes on chromosome 3q27-qter and independent replication of a type 2-diabetes locus on chromosome 1q21-q24. Am J Hum Genet 2000; 67(6): 1470-80. [http://dx.doi.org/10.1086/316887] [PMID: 11067779]

[69] Kondo H, Shimomura I, Matsukawa Y, et al. Association of adiponectin mutation with type 2 diabetes: A candidate gene for the insulin resistance syndrome. Diabetes 2002; 51(7): 2325-8. [http://dx.doi.org/10.2337/diabetes.51.7.2325] [PMID: 12086969]

[70] Pausova Z. From big fat cells to high blood pressure: A pathway to obesity-associated hypertension. Curr Opin Nephrol Hypertens 2006; 15(2): 173-8. [http://dx.doi.org/10.1097/01.mnh.0000214775.42103.a5] [PMID: 16481885]

[71] Gorzelniak K, Engeli S, Janke J, Luft FC, Sharma AM. Hormonal regulation of the human adipose-tissue renin-angiotensin system: Relationship to obesity and hypertension. J Hypertens 2002; 20(5): 965-73. [http://dx.doi.org/10.1097/00004872-200205000-00032] [PMID: 12011658]

[72] Schütten MT, Houben AJ, de Leeuw PW, Stehouwer CD. The link between adipose tissue renin-angiotensin-aldosterone system signaling "and obesity-associated hypertension. Physiology (Bethesda) 2017; 32(3): 197-209. [http://dx.doi.org/10.1152/physiol.00037.2016] [PMID: 28404736]

[73] Jung DH, Kim JY, Kim JK, Koh SB, Park JK, Ahn SV. Relative contribution of obesity and serum adiponectin to the development of hypertension. Diabetes Res Clin Pract 2014; 103(1): 51-6. [http://dx.doi.org/10.1016/j.diabres.2013.09.018] [PMID: 24398319]

[74] Kazumi T, Kawaguchi A, Sakai K, Hirano T, Yoshino G. Young men with high-normal blood pressure have lower serum adiponectin, smaller LDL size, and higher elevated heart rate than those with optimal blood pressure. Diabetes Care 2002; 25(6): 971-6. [http://dx.doi.org/10.2337/diacare.25.6.971] [PMID: 12032101]

[75] Iwashima Y, Katsuya T, Ishikawa K, et al. Hypoadiponectinemia is an independent risk factor for hypertension. Hypertension 2004; 43(6): 1318-23.

[http://dx.doi.org/10.1161/01.HYP.0000129281.03801.4b] [PMID: 15123570]

[76] Lin LY, Lin CY, Su TC, Liau CS. Angiotensin II-induced apoptosis in human endothelial cells is inhibited by adiponectin through restoration of the association between endothelial nitric oxide synthase and heat shock protein 90. FEBS Lett 2004; 574(1-3): 106-10. [http://dx.doi.org/10.1016/j.febslet.2004.08.012] [PMID: 15358548]

[77] Kinoshita M, Nakaya Y, Harada N, Takahashi A, Nomura M, Bando S. Combination therapy of exercise and angiotensin-converting enzyme inhibitor markedly improves insulin sensitivities in hypertensive patients with insulin resistance. Circ J 2002; 66(7): 655-8. [http://dx.doi.org/10.1253/circj.66.655] [PMID: 12135133]

[78] Iimura O, Shimamoto K, Matsuda K, et al. Effects of angiotensin receptor antagonist and angiotensin converting enzyme inhibitor on insulin sensitivity in fructose-fed hypertensive rats and essential hypertensives. Am J Hypertens 1995; 8(4 Pt 1): $353-7$. [http://dx.doi.org/10.1016/0895-7061(94)00245-7] [PMID: 7619347] 
[79] Ran J, Hirano T, Fukui T, et al. Angiotensin II infusion decreases plasma adiponectin level via its type 1 receptor in rats: An implication for hypertension-related insulin resistance. Metabolism 2006; 55(4): 478-88. [http://dx.doi.org/10.1016/j.metabol.2005.10.009] [PMID: 16546478]

[80] Furuhashi M, Ura N, Higashiura K, et al. Blockade of the renin-angiotensin system increases adiponectin concentrations in patients with essential hypertension. Hypertension 2003; 42(1): 76-81. [http://dx.doi.org/10.1161/01.HYP.0000078490.59735.6E] [PMID: 12796280]

[81] Konturek PC, Burnat G, Rau T, Hahn eg, Konturek S. Effect of adiponectin and ghrelin on apoptosis of Barrett adenocarcinoma cell line. Dig Dis Sci 2008; 53(3): 597-605.

[http://dx.doi.org/10.1007/s10620-007-9922-1] [PMID: 17763959]

[82] Park SH, Carrero JJ, Lindholm B, Stenvinkel P. Adiponectin in chronic kidney disease has an opposite impact on protein-energy wasting and cardiovascular risk: two sides of the same coin. Clin Nephrol 2009; 72(2): 87-96. [http://dx.doi.org/10.5414/CNP72087] [PMID: 19640365]

[83] Barazzoni R, Bernardi A, Biasia F, et al. Low fat adiponectin expression is associated with oxidative stress in nondiabetic humans with chronic kidney disease--impact on plasma adiponectin concentration. Am J Physiol Regul Integr Comp Physiol 2007; 293(1): R47-54. [http://dx.doi.org/10.1152/ajpregu.00745.2006] [PMID: 17363678]

[84] Tsioufis C, Dimitriadis K, Chatzis D, et al. Relation of microalbuminuria to adiponectin and augmented C-reactive protein levels in men with essential hypertension. Am J Cardiol 2005; 96(7): 946-51.

[http://dx.doi.org/10.1016/j.amjcard.2005.05.052] [PMID: 16188522]

[85] Sharma K, Ramachandrarao S, Qiu G, et al. Adiponectin regulates albuminuria and podocyte function in mice. J Clin Invest 2008; 118(5): 1645-56. [PMID: 18431508]

[86] Kacso IM, Bondor CI, Kacso G. Plasma adiponectin is related to the progression of kidney disease in type 2 diabetes patients. Scand J Clin Lab Invest 2012; 72(4): 333-9.

[http://dx.doi.org/10.3109/00365513.2012.668928] [PMID: 22486808]

[87] Tsigalou C, Chalikias G, Kantartzi K, et al. Differential effect of baseline adiponectin on all-cause mortality in hemodialysis patients depending on initial body mass index. Long-term follow-up data of 4.5 years. J Ren Nutr 2013; 23(1): 45-56. [http://dx.doi.org/10.1053/j.jrn.2011.12.007] [PMID: 22406123]

[88] Okuno S, Ishimura E, Norimine K, et al. Serum adiponectin and bone mineral density in male hemodialysis patients. Osteoporos Int 2012; 23(7): 2027-35. [http://dx.doi.org/10.1007/s00198-011-1789-5] [PMID: 21927917]

[89] Furukawa S, Fujita T, Shimabukuro M, et al. Increased oxidative stress in obesity and its impact on metabolic syndrome. J Clin Invest 2004; 114(12): 1752-61

[http://dx.doi.org/10.1172/JCI21625] [PMID: 15599400]

[90] Lee CH, Hung YJ. Possible new therapeutic approach for obesity-related diseases: Role of adiponectin receptor agonists. J Diabetes Investig 2015; 6(3): 264-6. [http://dx.doi.org/10.1111/jdi.12263] [PMID: 25969709]

[91] Kahn CR, Chen L, Cohen SE. Unraveling the mechanism of action of thiazolidinediones. J Clin Invest 2000; 106(11): $1305-7$. [http://dx.doi.org/10.1172/JCI11705] [PMID: 11104782]

[92] Janani C, Ranjitha Kumari BD. PPAR gamma gene--a review. Diabetes Metab Syndr 2015; 9(1): 46-50. [http://dx.doi.org/10.1016/j.dsx.2014.09.015] [PMID: 25450819]

[93] Yu JG, Javorschi S, Hevener AL, et al. The effect of thiazolidinediones on plasma adiponectin levels in normal, obese, and type 2 diabetic subjects. Diabetes 2002; 51(10): 2968-74. [http://dx.doi.org/10.2337/diabetes.51.10.2968] [PMID: 12351435]

[94] Maeda N, Takahashi M, Funahashi T, et al. PPARgamma ligands increase expression and plasma concentrations of adiponectin, an adiposederived protein. Diabetes 2001; 50(9): 2094-9. [http://dx.doi.org/10.2337/diabetes.50.9.2094] [PMID: 11522676]

[95] Okada-Iwabu M, Yamauchi T, Iwabu M, et al. A small-molecule AdipoR agonist for type 2 diabetes and short life in obesity. Nature 2013; 503(7477): 493-9.

[http://dx.doi.org/10.1038/nature12656] [PMID: 24172895]

[96] Yamauchi T, Nio Y, Maki T, et al. Targeted disruption of AdipoR1 and AdipoR2 causes abrogation of adiponectin binding and metabolic actions. Nat Med 2007; 13(3): 332-9. [http://dx.doi.org/10.1038/nm1557] [PMID: 17268472]

[97] Okada-Iwabu M, Iwabu M, Ueki K, Yamauchi T, Kadowaki T. Perspective of small-molecule AdipoR agonist for type 2 diabetes and short life in obesity. Diabetes Metab J 2015; 39(5): 363-72. [http://dx.doi.org/10.4093/dmj.2015.39.5.363] [PMID: 26566493]

[98] Yamauchi T, Kadowaki T. Adiponectin receptor as a key player in healthy longevity and obesity-related diseases. Cell Metab 2013; 17(2): $185-96$. 
[http://dx.doi.org/10.1016/j.cmet.2013.01.001] [PMID: 23352188]

[99] Kim B, Park KY, Ji Y, Park S, Holzapfel W, Hyun CK. Protective effects of Lactobacillus rhamnosus GG against dyslipidemia in high-fat diet-induced obese mice. Biochem Biophys Res Commun 2016; 473(2): 530-6. [http://dx.doi.org/10.1016/j.bbrc.2016.03.107] [PMID: 27018382]

[100] Kim SW, Park KY, Kim B, Kim E, Hyun CK. Lactobacillus rhamnosus GG improves insulin sensitivity and reduces adiposity in high-fat diet-fed mice through enhancement of adiponectin production. Biochem Biophys Res Commun 2013; 431(2): $258-63$. [http://dx.doi.org/10.1016/j.bbrc.2012.12.121] [PMID: 23313485]

\section{(C) 2018 Geagea et al.}

This is an open access article distributed under the terms of the Creative Commons Attribution 4.0 International Public License (CC-BY 4.0), a copy of which is available at: https://creativecommons.org/licenses/by/4.0/legalcode. This license permits unrestricted use, distribution, and reproduction in any medium, provided the original author and source are credited. 